\title{
Prognostic value of quantitative sensory testing in low back pain: a systematic review of the literature
}

This article was published in the following Dove Press journal:

Journal of Pain Research

6 September 2016

Number of times this article has been viewed

\author{
Anna Marcuzzi ${ }^{1,2}$ \\ Catherine M Dean ${ }^{1,2}$ \\ Paul J Wrigley ${ }^{3,4}$ \\ Rosemary J Chakiath ${ }^{3,4}$ \\ Julia M Hush ${ }^{1,2}$ \\ 'Discipline of Physiotherapy, \\ Department of Health Professions, \\ Faculty of Medicine and Health \\ Sciences, ${ }^{2}$ The Centre for Physical \\ Health, Macquarie University, Sydney, \\ ${ }^{3}$ Pain Management Research Institute, \\ Kolling Institute of Medical Research, \\ Royal North Shore Hospital, St \\ Leonards, ${ }^{4}$ Sydney Medical School - \\ Northern, University of Sydney, \\ Sydney, NSW, Australia
}

\begin{abstract}
Quantitative sensory testing (QST) measures have recently been shown to predict outcomes in various musculoskeletal and pain conditions. The aim of this systematic review was to summarize the emerging body of evidence investigating the prognostic value of QST measures in people with low back pain (LBP). The protocol for this review was prospectively registered on the International Prospective Register of Systematic Reviews. An electronic search of six databases was conducted from inception to October 2015. Experts in the field were contacted to retrieve additional unpublished data. Studies were included if they were prospective longitudinal in design, assessed at least one QST measure in people with LBP, assessed LBP status at follow-up, and reported the association of QST data with LBP status at follow-up. Statistical pooling of results was not possible due to heterogeneity between studies. Of 6,408 references screened after duplicates removed, three studies were finally included. None of them reported a significant association between the QST measures assessed and the LBP outcome. Three areas at high risk of bias were identified which potentially compromise the validity of these results. Due to the paucity of available studies and the methodological shortcomings identified, it remains unknown whether QST measures are predictive of outcome in LBP.
\end{abstract}

Keywords: prognosis, quantitative sensory testing, low back pain, cohort studies, pain, sensory testing

\section{Introduction}

The course of low back pain (LBP) is typically characterized by symptoms subsiding quickly within the first 4-6 weeks, but for some people there is little improvement thereafter. ${ }^{1}$ It has been estimated that up to $65 \%$ of people presenting to primary care for treatment of an episode of LBP still experience pain after 1 year. ${ }^{2}$ Persistent LBP has been identified as the world's leading cause of disability ${ }^{3}$ and remains a challenge in clinical management. ${ }^{4}$ Determining which factors predict outcomes in LBP would allow the identification of people at high risk of poor outcomes for whom early, targeted interventions could be beneficial. Several studies have evaluated the contribution of clinical, demographic, and psychosocial factors on functional recovery after LBP, ${ }^{5-8}$ but previous attempts to synthesize this body of research have led to inconsistent conclusions about which set of factors are useful for prognosis of LBP. ${ }^{9}$ Reasons for this uncertainty may include methodological limitations of the study design. ${ }^{10}$ However, another reason might be that we lack knowledge about potential factors that can provide useful prognostic information for LBP.

The prognostic value of quantitative sensory testing (QST) measures has more recently been investigated in musculoskeletal pain conditions. For example, cold and
Correspondence: Anna Marcuzzi Discipline of Physiotherapy, Department of Health Profession, Faculty of Medicine and Health Sciences, Macquarie University, Ground Floor, 75 Talavera Road, North Ryde, NSW 2109, Australia Tel +6I 298502798 Fax +6I 298506630 Email anna.marcuzzi@students.mq.edu.au 
mechanical pain hypersensitivity (pressure pain) have been shown to predict those at risk of poor outcome in both whiplash injury ${ }^{11-13}$ and lateral epicondylalgia. ${ }^{14}$ Evidence from cross-sectional studies has shown that specific QST measures can discriminate between people with chronic LBP and healthy controls. ${ }^{15-18}$ Further, we know that some abnormal QST findings can be detected soon after the onset of LBP. ${ }^{19}$ However, to date, there has been no review of the literature investigating the prognostic value of QST measures in LBP.

The aim of this systematic review is to identify, evaluate, and summarize the emerging body of literature investigating the prognostic ability of QST responses in LBP.

\section{Methods}

\section{Procedure}

This review was conducted in accordance with the Preferred Reporting Items for Systematic Reviews and Meta-Analyses statement guidelines. ${ }^{20}$ The protocol for this systematic review was prospectively registered on International Prospective Register of Systematic Reviews 2015 (registration number: CRD42015027228). Electronic searches for articles were conducted using the following databases from inception to October 2015: Ovid Medline, Ovid EMBASE, Ovid PsycINFO, Ovid Mantis, and Scopus. The PubMed database was also searched from January 2015 to October 2015 to retrieve recent literature not yet indexed in other databases. A comprehensive search strategy was designed with the assistance of an experienced research librarian and adjusted to account for differences in indexing across databases (Ovid Medline search is presented in Table S1). The search encompassed terms for the three domains of interest: LBP, QST, and prognosis. Terms for each domain were combined using the "AND" operator. The updated search strategy of the Cochrane Back Review Group $2013^{21}$ was used to identify back pain terms, while relevant terms for prognosis were based on those suggested by Altman ${ }^{10}$ and Hayden..$^{22}$ Reference lists of the included studies were screened to track other relevant literature. In addition, 21 experts in the field were contacted to identify any studies we had missed or to retrieve additional results from unpublished data. Non-English language studies, where a translation could be made available, were included.

\section{Study selection}

We included prospective longitudinal studies based on the following criteria: adults at least 18 years or older with acute ( $<6$ weeks), subacute (6-12 weeks), or chronic ( $>12$ weeks) nonspecific LBP with or without leg pain;23 participants had been assessed by at least one QST measure; LBP status at follow-up was reported; the association between QST responses at baseline and LBP outcomes at follow-up was reported; and the follow-up duration was a minimum of 1 week. No restrictions were placed on the setting or recruitment source of participants. We excluded LBP due to serious pathology (eg, fracture, neoplasm, and infection) or a specific condition (eg, rheumatoid arthritis, failed back surgery syndrome, pregnancy, postpartum back pain, and chronic widespread pain such as in fibromyalgia, irritable bowel syndrome) or after back surgery. Studies that investigated LBP together with other musculoskeletal pain disorders (eg, neck pain and thoracic pain) were also included if at least $>75 \%$ of the sample had LBP, or if data for LBP could be extracted separately.

The prognostic factors of interest were QST responses. The term QST was broadly used in this review to include psychophysical as well as specific electrophysiological tests. Psychophysical tests included "static" measures (eg, threshold determination to noxious and non-noxious stimuli and pain magnitude rating to suprathreshold stimuli) as well as "dynamic" measures (eg, temporal summation, conditioned pain modulation [CPM], and offset analgesia). ${ }^{24}$ Specific electrophysiological tests included assessment of nociceptive reflexes (eg, nociceptive withdrawal reflex).

The outcomes of interest were measures of LBP status at follow-up, including pain intensity, functional status or disability, work status, health-related quality of life, and global perceived effect/recovery.

\section{Study inclusion}

After removal of duplicate papers, studies that met the inclusion criteria were independently screened by two reviewers based on the title and then abstract. Finally, full-text articles were assessed for inclusion independently by two reviewers using a piloted standardized eligibility sheet, and any disagreements were resolved by discussion and consensus, and with the assistance of a third reviewer at all stages of screening. Reference lists of the included papers were screened to locate other relevant articles. Further, 21 experts in the field were contacted by email to retrieve any additional published or unpublished data.

\section{Risk of bias assessment}

The risk of bias was assessed independently by two reviewers using the Quality in Prognostic Studies tool developed by Hayden et $\mathrm{al}^{25}$ which was adapted for the needs of this systematic review, and incorporated additional criteria for assessment of bias in prognostic studies from other 
sources. ${ }^{10,26,27}$ Each of the six domains comprised multiple items that were individually scored as "yes", "no", "unclear", or "not applicable" and comments to support judgment were provided. The "yes" score within each domain was given only if the majority of items were fulfilled and indicated low risk of bias. Results of risk of bias assessment were summarized for each domain across studies. An overall risk of bias in each study (eg, summary score) was not provided in accordance with the current recommendations. ${ }^{28}$

\section{Data extraction and analysis}

Data from included studies were extracted independently by two reviewers using a piloted standardized data extraction sheet. Data extracted included information about study design, sample size, study population (eg, participant demographics and LBP features), recruitment source, inception time, follow-up duration, prognostic variables analyzed, outcome measures adopted, statistical analysis performed, and key findings. Any disagreement was resolved by discussion and consensus among the two reviewers.

Due to heterogeneity between studies with respect to LBP duration, clinical outcomes, follow-up duration, and statistical methods, it was not possible to statistically pool the results. Instead, findings were reported descriptively.

\section{Results}

The search strategy retrieved 8,628 articles from which 6,422 articles remained after duplicates were removed and 30 after screening by titles and abstracts. Full-text copies were then examined for eligibility (Figure 1). The reasons for exclusion at the full-text stage were: ineligible study design, QST assessment not performed, outcomes of LBP status at follow-up not reported, and ineligible participants. Three studies met the eligibility criteria and were therefore included.

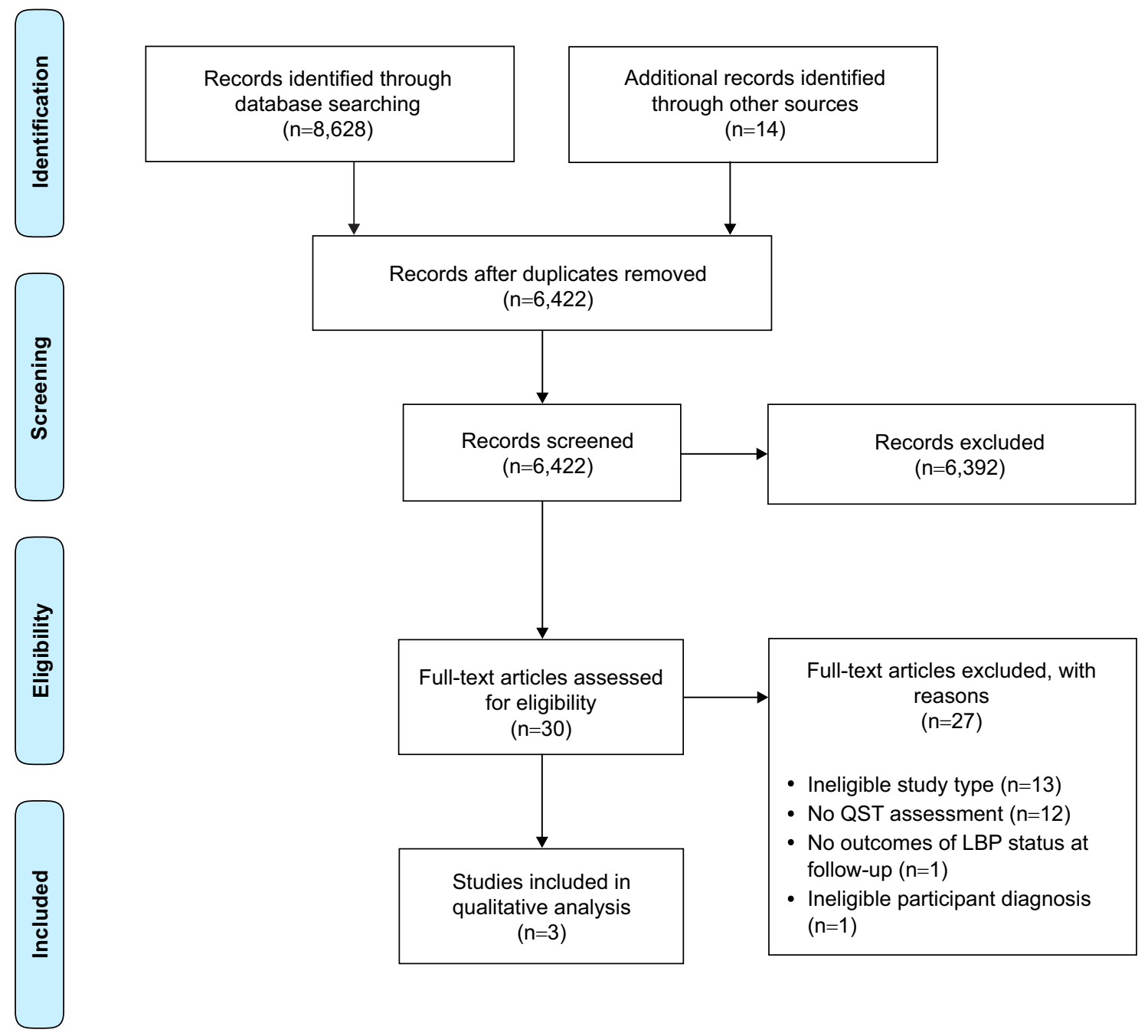

Figure I Preferred Reporting Items for Systematic Reviews and Meta-Analyses (PRISMA) flowchart. Abbreviations: LBP, low back pain; QST, quantitative sensory testing. 
An additional 14 studies from the reference lists of included studies were screened, but none were eligible for inclusion. None of the experts in the field who were contacted by the review team had data that fulfilled our criteria or were able to provide results from current prospective studies.

\section{Characteristics of samples in the included studies}

A description of the samples from the included studies is provided in Table 1. Two studies recruited patients with LBP from primary care practices ${ }^{29,30}$ and one study from tertiary care. ${ }^{31}$ LeResche et al $^{29}$ assessed 157 patients who made their first visit for mechanical LBP to a primary care clinic of the Group Health in the Seattle area (USA) who were followed up at 4 months. In this cohort, $65 \%$ of patients had LBP for less than 4 weeks, while the remaining $35 \%$ had a longer, variable duration of LBP. Mlekusch et $\mathrm{al}^{13}$ recruited 113 patients with chronic LBP without radicular pain, from a University Pain Clinic in Bern (Switzerland) who were followed up at 12-15 months. The authors reported that some patients received predominantly interventional treatments (eg, steroid injections, neural therapy, radiofrequency, surgery, acupuncture, and electrothermal therapy) between baseline assessment and follow-up. Nordeman et $\mathrm{al}^{30}$ investigated 113 females with chronic LBP with or without leg pain identified through a search of medical records of eight primary health care clinics in Sweden, and were followed up for 2 years after baseline assessment.

\section{Risk of bias assessment}

Regarding the risk of bias evaluation (Table 2), three domains with high risk of bias were identified across the three included studies, which potentially compromise the validity of these results. These domains were as follows: the representativeness of samples, the reporting of QST assessment, and the adequacy of the outcome measure. However, all three studies satisfactorily described their samples, had low attrition bias (follow-up rates more than 90\%), and reported statistical adjustment for relevant demographic or clinical/psychological factors.

\section{Association of QST findings with clinical outcomes}

All three studies investigated the association of pressure pain responses with LBP outcomes in univariate and multivariate analyses. LeResche et $\mathrm{al}^{29}$ found a significant association between pressure pain threshold (PPT) at the back and at the thenar eminence of the hand, with clinically significant

Table I Characteristics of samples in the included studies

\begin{tabular}{|c|c|c|c|}
\hline Characteristics & LeResche et $\mathrm{al}^{29}$ & Mlekusch et $\mathrm{al}^{31}$ & Nordeman et $\mathrm{al}^{30}$ \\
\hline Geographical area & USA (Seattle) & Switzerland & Sweden \\
\hline Setting & Primary care & Tertiary care & Primary care \\
\hline Population under study & Acute LBP & Chronic LBP & Chronic LBP \\
\hline Exclusion criteria for LBP & $\begin{array}{l}\text { LBP due to neoplastic, } \\
\text { infectious or inflammatory cause, } \\
\text { pregnancy or major trauma }\end{array}$ & $\begin{array}{l}\text { LBP with radicular pain confirmed by MRI } \\
\text { finding of nerve compression together with } \\
\text { symptoms or signs of nerve dysfunction }\end{array}$ & $\begin{array}{l}\text { LBP due to pregnancy, known spinal } \\
\text { disorders, or other severe disorders }\end{array}$ \\
\hline Female, n (\%) & $157^{a}(61.8)$ & $113(57)$ & $130(100)$ \\
\hline Mean age (SD), years & $47.4(12.4)$ & $50.8(15.4)$ & $45(10)$ \\
\hline $\begin{array}{l}\text { Mean pain duration }(S D) \text {, } \\
\text { years }\end{array}$ & LBP $\leq 30$ days (in $65 \%$ of sample) & $6.1(6.4)$ & $9.6(8.8)$ \\
\hline Follow-up duration & 4 months & 12 to 15 months & 2 years \\
\hline Loss to follow-up (\%) & 6 & 0 & 5 \\
\hline Events, $\mathrm{n}(\%)^{\mathrm{b}}$ & $44(30)$ & $\mathrm{N} / \mathrm{A}$ & $27(22)$ \\
\hline
\end{tabular}

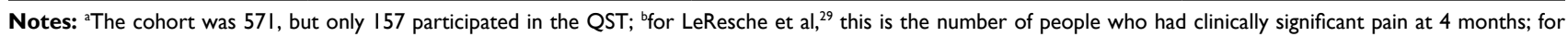
Nordeman et al, ${ }^{30}$ this is the number of people who were in the "no work ability" category at 2 years.

Abbreviations: LBP, low back pain; SD, standard deviation; N/A, not applicable; MRI, magnetic resonance imaging; QST, quantitative sensory testing.

Table 2 Risk of bias assessment using the adapted version of the QUIPS tool

\begin{tabular}{|c|c|c|c|c|c|c|c|}
\hline \multirow[t]{2}{*}{ Reference } & \multicolumn{2}{|c|}{ Sampling } & \multirow{2}{*}{$\begin{array}{l}\text { Study } \\
\text { attrition }\end{array}$} & \multirow{2}{*}{$\begin{array}{l}\text { Prognostic } \\
\text { factors } \\
\text { measurement }\end{array}$} & \multirow{2}{*}{$\begin{array}{l}\text { Outcome } \\
\text { measurement }\end{array}$} & \multirow{2}{*}{$\begin{array}{l}\text { Study } \\
\text { confounding }\end{array}$} & \multirow{2}{*}{$\begin{array}{l}\text { Statistical } \\
\text { analysis and } \\
\text { reporting }\end{array}$} \\
\hline & $\begin{array}{l}\text { Sample } \\
\text { defined }\end{array}$ & $\begin{array}{l}\text { Sample } \\
\text { representative }\end{array}$ & & & & & \\
\hline LeResche et $\mathrm{al}^{29}$ & Yes & Unclear & Yes & Unclear & Yes & Yes & Yes \\
\hline Mlekusch et $\mathrm{al}^{31}$ & Yes & No & Yes & Yes & Yes & Yes & Yes \\
\hline Nordeman et $\mathrm{al}^{30}$ & Yes & Unclear & Yes & Unclear & Unclear & Yes & Yes \\
\hline
\end{tabular}

Abbreviation: QUIPS, Quality in Prognostic Studies. 
pain intensity at 4 months (odds ratio [OR]: 0.66 [95\% CI $0.44-0.96$ ] and 0.62 [95\% CI 0.40-0.92], respectively). However, this association was not significant when adjusted for age and sex in the multivariate model. In a study by Nordeman et $\mathrm{al},{ }^{30}$ results from the univariate analysis revealed that people with chronic LBP with higher PPT - measured at eight tender points - were significantly more likely to be able to work at 2 years (OR: 1.4 [95\% CI 1.1-1.9]). In the multivariate analysis, when age; functional status; psychological, environmental, and health-related factors; activity; and participation limitations were entered into the model as independent variables, PPT was no longer a significant independent predictor of work status at 2 years. However, reduced walking speed (measured by the 6-minute walk test), higher depression (measured by the Hospital Anxiety and Depression Scale-depression subscale), and previous inability to work remained in the final model, explaining $51 \%$ of the variance in the outcome at 2 years. Mlekusch et $\mathrm{al}^{31}$ found no association of pressure pain tolerance threshold measured at the toe with change in pain intensity at $12-15$ months in people with chronic LBP, when controlling for baseline pain intensity $(r=0.03[95 \%$ CI -0.21-0.28). When adjusted for demographics and psychological and clinical variables, the association remained nonsignificant ( $r=-0.01$ [95\% CI $-0.28-0.27]$ ).

The prognostic value of cold pressor testing was reported in two studies. In LeResche et al, ${ }^{29}$ cold pain sensitivity was assessed as the average pain intensity at 10,20, and 30 seconds after immersion of the hand in cold water at $4^{\circ} \mathrm{C}-5^{\circ} \mathrm{C}$. In both the univariate and adjusted analyses, there was no significant association of cold pressor pain rating with clinically significant pain at 4 months (OR: 1.04 [95\% CI 0.72-1.51] and 0.91 [95\% CI 0.61-1.36], respectively). In Mlekusch et al, ${ }^{31}$ cold pain tolerance was measured as the time participants could tolerate immersion of their hand in cold water at $0^{\circ} \mathrm{C}$ (up to a maximum of 2 minutes). The association of cold pain tolerance with change in pain intensity at $12-15$ months was near null in both the univariate $(r=-0.02$ [95\% CI $-0.23-0.28])$ and adjusted analyses $(r=-0.00$ [95\% CI $-0.26-0.25])$.

CPM was assessed in two studies, ${ }^{29,31}$ with noxious cold water as the conditioning stimulus in both studies. In LeResche et $\mathrm{al},{ }^{29}$ heat pain was used as the test stimulus, measured before and again during immersion of the hand in cold water. In Mlekusch et al, ${ }^{31}$ pressure pain tolerance was used as the test stimulus measured before and again after removal of the hand from the cold water. The CPM response was measured as the difference between heat pain rating and pain threshold, before and after the conditioning stimulus. Both studies reported no association of the CPM response with outcomes in the acute (OR: 1.11 [95\% CI 0.77-1.62]) and chronic ( $r=-0.40$ [95\% CI -0.80-0.00]) LBP samples studied.

Finally, one study ${ }^{29}$ assessed mechanical temporal summation using repeated application of a von Frey filament at the forearm. No significant association was observed between temporal summation and clinically significant pain at 4 months, in both the univariate (OR: 0.92 [95\% CI 0.63-1.31]) and adjusted (OR: 0.88 [95\% CI 0.58-1.27]) analyses. A summary of these results is presented in Table 3 .

\section{Discussion}

This systematic review has revealed a surprising finding that there are very few studies which investigated the prognostic value of QST responses in people with LBP. In the three studies that were included in this review, none reported any significant association between the QST responses tested and LBP outcomes measured between 4 months and 2 years in both acute and chronic LBP.

Other studies have reported negative findings between QST responses and LBP outcomes. For example, in a systematic review of cross-sectional analyses, no correlation was found between QST responses and spinal pain and disability, regardless of the QST modality used, the site of assessment, or pain duration. ${ }^{32}$ The authors of the review noted this observed finding may be because pain thresholds (eg, pressure pain detection threshold) were predominantly assessed in the included studies, rather than suprathreshold or dynamic QST tests. In another example, O'Neill et al ${ }^{33}$ investigated risk factors for LBP in the general population, and found that people with lower PPT (below the 10th percentile of PPT distribution) were not at higher risk of developing future LBP. Whether or not this result would have been different if suprathreshold measures of pain sensitivity were used is unknown. However, if indeed dynamic QST tests are more clinically relevant measures of pain sensitivity, then we would have expected an association in the studies reporting these measures in the current review. One explanation could be the low prevalence of pain hypersensitivity in the cohorts investigated. Indeed, one of the three studies ${ }^{31}$ in this review did report that only a small proportion of people (approximately 25\%) with severe longlasting LBP had QST responses below the 10th percentile of normative data distribution, indicative of widespread pain hypersensitivity. It remains unknown whether this may have been a factor in the other two studies as prevalence data regarding pain hypersensitivity were not available.

When prospective studies investigating other pain conditions were examined, there are examples where QST 
Table 3 Summary of the main findings

\begin{tabular}{|c|c|c|c|c|c|c|c|c|}
\hline Reference & Stimulus & $\begin{array}{l}\text { Pain } \\
\text { measure }\end{array}$ & Site & Other variables & $\begin{array}{l}\text { Outcome } \\
\text { measure }\end{array}$ & $\begin{array}{l}\text { Statistical } \\
\text { analysis }\end{array}$ & $\begin{array}{l}\text { Results } \\
\text { (univariate } \\
\text { analyses ) } \\
\end{array}$ & Conclusions \\
\hline $\begin{array}{l}\text { LeResche } \\
\text { et } \mathrm{al}^{29}\end{array}$ & $\begin{array}{l}\text { Mechanical } \\
\text { CPM }\end{array}$ & $\begin{array}{l}\text { Pain } \\
\text { threshold } \\
\text { Pain } \\
\text { magnitude } \\
\text { rating } \\
\text { Temporal } \\
\text { summation } \\
\text { Cold bath } \\
\text { (CS) and heat } \\
\text { pain (TS) }\end{array}$ & $\begin{array}{l}\text { Back and hand } \\
\text { Hand } \\
\text { Forearm } \\
\text { Hand (CS) and } \\
\text { forearm (TS) }\end{array}$ & $\begin{array}{l}\text { Age } \\
\text { Sex }\end{array}$ & $\begin{array}{l}\text { Clinical } \\
\text { significant pain } \\
\text { measured by } \\
\text { the Graded } \\
\text { Chronic Pain } \\
\text { Scale: "no" } \\
\text { defined as grade } \\
0 \text { or I; "yes" } \\
\text { defined as grade } \\
\text { II, III, IV }\end{array}$ & $\begin{array}{l}\text { Univariate } \\
\text { and } \\
\text { multivariable } \\
\text { logistic } \\
\text { regression }\end{array}$ & $\begin{array}{l}\text { Only PPT at the } \\
\text { back and PPT } \\
\text { at the thenar } \\
\text { eminence were } \\
\text { significantly } \\
\text { associated } \\
\text { with clinically } \\
\text { significant pain at } \\
4 \text { months }(P<0.5)\end{array}$ & $\begin{array}{l}\text { None of the } \\
\text { QST measures } \\
\text { were significant } \\
\text { predictors } \\
\text { of clinical } \\
\text { significant pain } \\
\text { at } 4 \text { months } \\
\text { after controlling } \\
\text { for patient age } \\
\text { and sex }\end{array}$ \\
\hline $\begin{array}{l}\text { Mlekusch } \\
\text { et } \mathrm{al}^{31}\end{array}$ & $\begin{array}{l}\text { Pressure } \\
\text { Cold } \\
\text { CPM }\end{array}$ & $\begin{array}{l}\text { Pain } \\
\text { tolerance } \\
\text { Pain } \\
\text { tolerance } \\
\text { (time to } \\
\text { withdrawal) } \\
\text { Cold bath } \\
\text { (CS) and } \\
\text { PPtol (TS) }\end{array}$ & $\begin{array}{l}\text { Hand (CS) and } \\
\text { toe (TS) }\end{array}$ & $\begin{array}{l}\text { Pain severity and } \\
\text { duration, age, sex, } \\
\text { catastrophizing, } \\
\text { depression, intake } \\
\text { of opioids }\end{array}$ & $\begin{array}{l}\text { Change score } \\
\text { in average pain } \\
\text { intensity over } \\
\text { the last } 24 \\
\text { hours measured } \\
\text { by numeric } \\
\text { rating scale } \\
\text { (NRSII) }\end{array}$ & $\begin{array}{l}\text { Univariate } \\
\text { and } \\
\text { multivariable } \\
\text { linear } \\
\text { regression }\end{array}$ & $\begin{array}{l}\text { None of the QST } \\
\text { variables showed } \\
\text { an association } \\
\text { with change score } \\
\text { in pain severity at } \\
\text { I year }\end{array}$ & $\begin{array}{l}\text { None of } \\
\text { the QST } \\
\text { measures were } \\
\text { significantly } \\
\text { associated with } \\
\text { change score in } \\
\text { pain severity at } \\
\text { I year in both } \\
\text { the unadjusted } \\
\text { and adjusted } \\
\text { analyses }\end{array}$ \\
\hline $\begin{array}{l}\text { Nordeman } \\
\text { et } \mathrm{al}^{30}\end{array}$ & Pressure & $\begin{array}{l}\text { Pain } \\
\text { threshold }\end{array}$ & $\begin{array}{l}\text { Trapezius, } \\
\text { supraspinatus, } \\
\text { gluteal, and } \\
\text { knee bilaterally }\end{array}$ & $\begin{array}{l}\text { Age, baseline } \\
\text { work ability, } \\
\text { walking test, hand } \\
\text { grip strength, } \\
\text { number of pain } \\
\text { localizations, } \\
\text { widespread pain, } \\
\text { pain severity, } \\
\text { fatigue, activity } \\
\text { limitation, } \\
\text { social support, } \\
\text { risk of long- } \\
\text { term disability, } \\
\text { stress, anxiety, } \\
\text { depression, } \\
\text { general health } \\
\text { status }\end{array}$ & $\begin{array}{l}\text { Work ability: } \\
\text { "no" defined } \\
\text { as full-time sick } \\
\text { leave or full- } \\
\text { time disability } \\
\text { pension; "yes" } \\
\text { defined as } \\
\text { work or study, } \\
\text { applying for } \\
\text { work, parental } \\
\text { leave, or part- } \\
\text { time disability } \\
\text { pension }\end{array}$ & $\begin{array}{l}\text { Univariate } \\
\text { and forward } \\
\text { stepwise } \\
\text { logistic } \\
\text { regression }\end{array}$ & $\begin{array}{l}\text { PPT was } \\
\text { significantly } \\
\text { associated with } \\
\text { work ability at } 2 \\
\text { years }(P=0.018)\end{array}$ & $\begin{array}{l}\text { Walking ability } \\
\text { together with } \\
\text { depression } \\
\text { score and } \\
\text { baseline work } \\
\text { ability were } \\
\text { significant } \\
\text { predictors } \\
\text { accounting for } \\
51 \% \text { of the } \\
\text { variance in work } \\
\text { ability at } 2 \text { years }\end{array}$ \\
\hline
\end{tabular}

Abbreviations: PPT, pressure pain threshold; CPM, conditioned pain modulation; PPtol, pressure pain tolerance; CS, conditioning stimulus; TS, test stimulus; QST, quantitative sensory testing.

responses do predict outcomes. For example, cold pain hypersensitivity and PPTs have been found to be of prognostic value in both whiplash-associated disorders ${ }^{11-13}$ and lateral epicondylalgia. ${ }^{14}$ Further, a recent systematic review showed that responses to psychophysical tests (ie, lower thermal, mechanical, and electrical pain tolerances or thresholds) explained up to $54 \%$ of the variance in postoperative pain following gynecological, orthopedic, and thoracotomy surgical procedures. ${ }^{34}$ For example, cold pain tolerance measured preoperatively was identified as an independent risk factor for early postoperative pain in cholecystectomy. ${ }^{35}$ While these studies in musculoskeletal and perioperative pain have shown an association of QST findings with outcome, the overall number of prospective studies examining the predictive capacity of QST to identify those at greatest risk of persistent pain and poor functional outcomes remains small; therefore, further research is needed to confirm these results.

In the studies included in the present review, a number of methodological limitations that need to be taken into consideration when interpreting these findings were identified. The first concern was the "representativeness of the samples". It is well established that the most useful prognostic studies are those which assemble an inception cohort, ${ }^{26,27}$ yet only survivor cohorts were recruited in the studies in this review. 
For example, in two studies ${ }^{30,31}$ the participants had chronic LBP with a mean pain duration of 9.6 (standard deviation [SD] 8.8) years and 6.1 (SD 6.4) years. One study ${ }^{29}$ attempted to assemble a LBP cohort of less than 30 days duration. However, $35 \%$ of the participants had duration longer than 30 days, and the pain duration details were not provided for this sample. Further, in Mlekusch et al, ${ }^{31}$ only patients seeking care to a pain clinic were included, which further limited the generalizability of these results. ${ }^{26}$ The second methodological issue pertains to the "measurement of prognostic factors". It was mostly unclear whether QST measures were performed in the same manner for all participants since information about the test protocol (eg, patient positioning, order of the tests, description of assessor training, number of assessors, and use of standardized instructions) as well as blinding of QST assessors were not reported. Standardized testing procedures ensure adequate reliability of QST measures. ${ }^{36,37}$ Poor reliability of QST measures can dilute or mask prognostic information. ${ }^{38}$ The last methodological issue is the "adequacy of the outcome measures". In Nordeman et al, ${ }^{30}$ the validity of the applied work status categories is unclear (eg, part-time disability pension was classified as "able to work"). Moreover, the responsiveness of the work outcome used in this survivor cohort of chronic LBP was low, as illustrated by the low change (1\%) in people's ability to work from baseline to 2 years.

\section{Strengths and limitations}

The strengths of this systematic review were that the research question was well defined with respect to the study design, population of interest, prognostic variables, and outcomes, and a thorough search strategy was used to identify all possible studies including unpublished data. The main limitations were that only a small number of studies met the inclusion criteria and they were heterogeneous with regard to LBP duration, clinical outcomes, follow-up duration, and statistical methods, which precluded quantitative analysis. In addition, the studies only assessed a limited range of QST measures, namely, mechanical and cold pain threshold and tolerance, temporal summation, and CPM. Therefore, it is not known whether other test modalities alone or in combination may have prognostic value in LBP. Additionally, the risk of bias issues discussed earlier further limit the generalizability of the findings.

\section{Future perspectives}

Future studies that aim to investigate the prognostic value of QST measures should focus on an inception cohort design, employ multiple QST modalities that are comprehensively described, and use standardized protocols, blinded assessors, and validated and appropriate outcome measures. Additionally, it would be valuable to concurrently assess known clinical and psychosocial predictors to account for the complexity and heterogeneity of LBP.

\section{Conclusion}

Due to the paucity of prospective cohort studies and the methodological shortcomings of available studies, it remains unknown whether QST measures are predictive of outcome in LBP. Given the developing body of literature suggesting QST as prognostic value for pain and function in various pain conditions, future prospective prognostic outcome studies of QST in LBP would be worthwhile.

\section{Disclosure}

The authors report no conflicts of interest in this work.

\section{References}

1. Vasseljen O, Woodhouse A, Bjørngaard JH, Leivseth L. Natural course of acute neck and low back pain in the general population: the HUNT study. Pain. 2013;154(8):1237-1244.

2. Itz C, Geurts J, Kleef Mv, Nelemans P. Clinical course of non-specific low back pain: a systematic review of prospective cohort studies set in primary care. Euro J Pain. 2013;17(1):5-15.

3. Hoy D, March L, Brooks P, et al. Measuring the global burden of low back pain. Best Pract Res Clin Rheumatol. 2010;24(2):155-165.

4. Artus M, van der Windt DA, Jordan KP, Hay EM. Low back pain symptoms show a similar pattern of improvement following a wide range of primary care treatments: a systematic review of randomized clinical trials. Rheumatology (Oxford). 2010;49(12):2346-2356.

5. Grotle M, Brox JI, Veierød MB, Glomsrød B, Lønn JH, Vøllestad NK. Clinical course and prognostic factors in acute low back pain: patients consulting primary care for the first time. Spine. 2005;30(8):976-982.

6. Burton AK, Tillotson KM, Main CJ, Hollis S. Psychosocial predictors of outcome in acute and subchronic low back trouble. Spine. 1995;20(6):722-728.

7. Henschke N, Maher CG, Refshauge KM, et al. Prognosis in patients with recent onset low back pain in Australian primary care: inception cohort study. BMJ. 2008;337:a171.

8. Deyo RA, Diehl AK. Psychosocial predictors of disability in patients with low back pain. J Rheumatol. 1988;15(10):1557-1564.

9. Hayden J, Chou R, Hogg-Johnson S, Bombardier C. Systematic reviews of low back pain prognosis had variable methods and results - guidance for future prognosis reviews. J Clin Epidemiol. 2009;62(8):781-796.e1.

10. Altman DG. Systematic reviews of evaluations of prognostic variables. BMJ. 2001;323(7306):224-228.

11. Sterling M, Jull G, Vicenzino B, Kenardy J, Darnell R. Physical and psychological factors predict outcome following whiplash injury. Pain 2005;114(1):141-148.

12. Kasch H, Qerama E, Bach FW, Jensen TS. Reduced cold pressor pain tolerance in non-recovered whiplash patients: a 1-year prospective study. Euro J Pain. 2005;9(5):561-561.

13. Walton D, MacDermid J, Nielson W, Teasell R, Reese H, Levesque L. Pressure pain threshold testing demonstrates predictive ability in people with acute whiplash. J Orthop Sports Phys Ther. 2011;41(9):658-665.

14. Coombes BK, Bisset L, Vicenzino B. Cold hyperalgesia associated with poorer prognosis in lateral epicondylalgia: a 1-year prognostic study of physical and psychological factors. Clin J Pain. 2015;31(1):30-35. 
15. Neziri AY, Curatolo M, Limacher A, et al. Ranking of parameters of pain hypersensitivity according to their discriminative ability in chronic low back pain. Pain. 2012;153(10):2083-2091.

16. Giesbrecht RJS, Battié MC. A comparison of pressure pain detection thresholds in people with chronic low back pain and volunteers without pain. Phys Ther. 2005;85(10):1085-1092.

17. Puta C, Schulz B, Schoeler S, et al. Enhanced sensitivity to punctate painful stimuli in female patients with chronic low back pain. $B M C$ Neurol. 2012;12(1):1.

18. O’Neill S, Manniche C, Graven-Nielsen T, Arendt-Nielsen L. Generalized deep-tissue hyperalgesia in patients with chronic low-back pain. Euro J Pain. 2007;11(4):415-420.

19. Marcuzzi A, Dean CM, Wrigley PJ, Hush JM. Early changes in somatosensory function in spinal pain: a systematic review and meta-analysis. Pain. 2015;156(2):203-214.

20. Moher D, Liberati A, Tetzlaff J, Altman DG; PRISMA Group. Preferred reporting items for systematic reviews and meta-analyses: the PRISMA statement. Int J Surg. 2010;8(5):336-341.

21. Bombardier C, van Tulder M, Bronfort G, Chou R, Corbin T, Deyo R; Cochrane Back Group. About the Cochrane Collaboration (Cochrane Review Groups (CRGs)). 2014; Issue 1. Art. No.: BACK. Available from: https://back.cochrane.org/sites/back.cochrane.org/files/uploads/ PDF/CBRG\%20Search\%20Strategies\%20Jan\%202013.pdf. Accessed August 25, 2016.

22. Hayden JA, Tougas ME, Riley R, Iles R, Pincus T. Individual recovery expectations and prognosis of outcomes in non-specific low back pain: prognostic factor exemplar review. Cochrane Database Syst Rev. 2014:CD011284.

23. Van Tulder M, Becker A, Bekkering T, et al. Chapter 3: European guidelines for the management of acute nonspecific low back pain in primary care. Euro Spine J. 2006;15:s169-s191.

24. Arendt-Nielsen L, Yarnitsky D. Experimental and clinical applications of quantitative sensory testing applied to skin, muscles and viscera. J Pain. 2009;10(6):556-572.

25. Hayden JA, van der Windt DA, Cartwright JL, CÃ P, Bombardier C. Assessing bias in studies of prognostic factors. Ann Intern Med. 2013;158(4):280-286.

26. Beattie PF, Nelson RM. Evaluating research studies that address prognosis for patients receiving physical therapy care: a clinical update. Phys Ther. 2007;87(11):1527-1535.
27. Straus SE, Richardson WS, Glasziou P, Haynes RB. Evidence-Based Medicine: How to Practice and Teach EBM. Edinburgh: Churchill Livingstone; 2005.

28. Higgins J, Green S. Cochrane Handbook for Systematic Reviews of Interventions Version 5.1. 0 [Updated March 2011]. The Cochrane Collaboration. 2011. Available from: http://handbook.cochrane.org/. Accessed August 25, 2016.

29. LeResche L, Turner JA, Saunders K, Shortreed SM, Von Korff M. Psychophysical tests as predictors of back pain chronicity in primary care. J Pain. 2013;14(12):1663-1670.

30. Nordeman L, Gunnarsson R, Mannerkorpi K. Prognostic factors for work ability in women with chronic low back pain consulting primary health care: a 2-year prospective longitudinal cohort study. Clin J Pain. 2014;30(5):391-398.

31. Mlekusch S, Schliessbach J, Camara RJ, Arendt-Nielsen L, Jüni P, Curatolo M. Do central hypersensitivity and altered pain modulation predict the course of chronic low back and neck pain? Clin J Pain. 2013;29(8):673-680

32. Hübscher M, Moloney N, Leaver A, Rebbeck T, McAuley JH, Refshauge KM. Relationship between quantitative sensory testing and pain or disability in people with spinal pain - a systematic review and metaanalysis. Pain. 2013;154(9):1497-1504.

33. O’Neill S, Kjær P, Graven-Nielsen T, Manniche C, Arendt-Nielsen L. Low pressure pain thresholds are associated with, but does not predispose for, low back pain. Euro Spine J. 2011;20(12):2120-2125.

34. Werner MU, Mjöbo HN, Nielsen PR, Rudin Å. Prediction of postoperative pain. a systematic review of predictive experimental pain studies. J Am Soc Anesthesiol. 2010;112(6):1494-1502.

35. Bisgaard T, Klarskov B, Rosenberg J, Kehlet H. Characteristics and prediction of early pain after laparoscopic cholecystectomy. Pain. 2001;90(3):261-269.

36. Geber C, Klein T, Azad S, et al. Test-retest and interobserver reliability of quantitative sensory testing according to the protocol of the German Research Network on Neuropathic Pain (DFNS): a multi-centre study. Pain. 2011;152(3):548-556.

37. Backonja MM, Attal N, Baron R, et al. Value of quantitative sensory testing in neurological and pain disorders. Pain. 2013;154(9): 1807-1819.

38. Royston P, Moons KG, Altman DG, Vergouwe Y. Prognosis and prognostic research: developing a prognostic model. BMJ. 2009;338:b604. 


\section{Supplementary material}

Table SI Ovid Medline search

I. exp cohort studies/

2. incidence/

3. follow up stud*.mp.

4. prognos*.mp.

5. predict*.mp.

6. course.mp.

7. inception.mp.

8. exp survival analysis/

9. $\exp$ risk/

10. observational study/

II. longitudinal studies/

I2. or/I-II

13. back pain/

14. low back pain/

15. back disorder*.mp.

16. (lumbar adj pain).ti,ab.

17. sciatica/

18. sciatic neuropathy/

19. Intervertebral Disc Degeneration/

20. (dis* adj I prolapse*).ti,ab.

2I. (dis* adjl herniat*).ti,ab.

22. (facet adj joint*).ti,ab.

23. backache.ti,ab.

24. dorsalgia.mp.

25. or/13-24

26. exp Pain Perception/

27. pain, referred/

28. allodynia.ti,ab.

29. neuralgia/

30. hypersensit*.mp.

31. hyperpathia.ti,ab.

32. exp somatosensory disorders/

33. sensory profile*.mp.

34. hyp?algesia.ti,ab.

35. hyperalg?esia.ti,ab.

36. paresth?esia.ti,ab.

37. hyperesth?esia.ti,ab.

38. dysesth?esia.ti,ab.
39. hyp? esthesia.ti,ab.

40. peripheral sensit*.ti,ab.

4I. central sensit*.ti,ab.

42. spinal sensit*.ti,ab.

43. central pain.ti,ab.

44. (quantitative sensory test* or QST).mp.

45. experim* pain.mp.

46. ((pain adj test*) or (pain adj measure*)).mp.

47. bedside exam*.mp.

48. psychophysic*.mp.

49. Electrophysiologic*.mp.

50. (temporal summation or windup or wind up).mp.

5I. (second* adj pain).ti,ab.

52. (two-point discrimination or TPD).mp.

53. tactile acuity.ti,ab.

54. (cold pressor test or CPT).mp.

55. (diffuse noxious inhibitory control or DNIC).mp.

56. (pain modul* or descending modul*).mp.

57. (conditioned pain modulation or CPM).mp.

58. offset analgesia.mp.

59. neural inhibition/

60. (nociceptive withdrawal reflex or NWR or nociceptive flexion reflex or NFR).mp.

6I. (reflex receptive field or RRF).mp.

62. (spinal reflex* or (RIII adj reflex)).mp.

63. pain threshold/

64. Nociceptors/

65. ((pressure or thermal or cold or heat or eletrical or mechanical) adj pain).ti,ab. [mp=title, abstract, original title, name of substance word, subject heading word, keyword heading word, protocol supplementary concept word, rare disease supplementary concept word, unique identifier]

66. ((cold or warm) adj detection).ti,ab.

67. ((pain adj2 tolerance) or (pain adj2 processing) or detection threshold).ti,ab.

68. or $/ 26-67$

69. 12 and 25 and 68

70. 69 not randomized controlled trial/
Journal of Pain Research

\section{Publish your work in this journal}

The Journal of Pain Research is an international, peer reviewed, open access, online journal that welcomes laboratory and clinical findings in the fields of pain research and the prevention and management of pain. Original research, reviews, symposium reports, hypothesis formation and commentaries are all considered for publication.
The manuscript management system is completely online and includes a very quick and fair peer-review system, which is all easy to use. Visit http://www.dovepress.com/testimonials.php to read real quotes from published authors. 